\title{
SUBJETIVIDAD E HISTORIA. DESCARTES LEÍDO CUATRO SIGLOS DESPUÉS
}

\author{
Dr. Mario Casalla \\ (U. de Buenos Aires y Asociación de Filosofia Latinoamericana y Ciencias Sociales)
}

Bien sabemos, aunque nos cueste aceptarlo, que la lectura no es precisamente una operación ingenua. Tarea esencialmente interpretativa y restaurativa, tiene en el sujeto que la cjerce una de sus claves más importantes. De aqui que las nociones de texto y autor estén siempre mediadas por la presencia de ese irremediable intruso que es el "lector", al cual todos los textos le son of recidos y ocultados simultáneamente; obligándolo a fijar —de manera provisoria y abierta- aquello "de lo que se trata", a partir de una intertertualidad siempre evanescente. Paradójicamente, acaso en esta aparente limitación, finquen el carácter siempre fascinante de la lectura, la posibilidad de materializarla en textos y corporizarla en autores.

Es que toda lectura está irremediablemente situada, a punto tal que el reconocimiento de esta situacionalidad es más un privilegio que una carencia, una oportunidad de entender, antes que el trastoque de alguna supuesta "objetividad" autosuficiente.1

$Y$ esta situación desde la que leemos - en nuestro caso a Renato Descartes- es siempre cultural e histórica. Queremos decir con esto, que comprende no sólo al actor individual del hecho, sino al contexto y al momento que precisamente lo fundan como lector a uno y como autor al otro. El resultado es un constructo en el cual emerge "nuestro Descartes", al mismo tiempo que nos fundamos como sus "contemporáneos".2

Leemos siempre desde una cultura y una historia que - en el caso de nuestro presentetiene caracteristicas, urgencias y tareas globales muy especificas, aunque raigalmente conectadas con ese largo camino que Descartes iniciaria hace ya cuatro siglos.

Leemos a Descartes de y desde los tiempos de la modernidad consumada, en que la figura de la técnica se dibuja a escala planetaria y el equivoco debate postmoderno seinala más una dirección que un resultado visible. ${ }^{3} Y$ no es lo mismo esta lectura que otra.

Más aún, dentro de esta misma globalidad propia del presente, no es lo mismo /eer a Descartes en y desde la tradición de la filosofia europea, que desde nuestra siempre equivoca -poco "clara y distinta"- realidad latinoamericana.

Sin embargo ahora y a los efectos de una mejor comunicación, postergaré esta última distinción y me ubicaré en la perspectiva común de estos tiempos de la modernidad consumada que, signados por la técnica, compartimos planetariamente.

I De nuestra pane venimos distinguiendo (1973) entre un universal abstracto y un unirersal sifusdo y plante. ando, en consecuencia, la necesidad de una lectura culuroluteme simada en filosofia. La aplicación de esle inćstodo de lectura dio por resultado - entre otros- nuestros trabajos Crisis de Europa y reconstruccion del hombre. Un ensquo sobre Afartin Heidegger (Castaneda, Bs Aires, 1977) y America en el pensamieno de Hegel. Admiraciony rechazo (Catálogos, Bs Aires, 1992). Desde ya seralamos sintéticamente aqui que, lo que pensamos bajo la denominación "universal situado", no se limita a la categorja hegeliana de lo "universal concreto" (antes bien, pretende avanzar más allá de la ontologia moderna que la sustenta); asf como la noción de "situación" no es utilizada con el valor simple de mero contexto, o "condiciones de la época", sino mós bien como pro-yecio.

2 En este sentido vale la intención de Bảrbara Cassin de hablamos de "estrategias contemporáneas de aprobación" (Nos Grecs et leturs modernes. Les stratégies contemporaines d'appropiation de l'antiquete, Seuil, Paris, 1992; resultado del coloquio homónimo real izado en octubre de 1990). Dentro de ese espiritu de "apropiación contemporínea" se mueve también nuestra lectum cantesiana.

3 En cuanto a lo de "equíroco", vale aqui recordar aquėlla advenencia de J. Derrida en De la Grammatologie: "no se sale de la época cuya clausura quede esbozarse" aún. 


\section{Una primera distinción}

Decíamos que Descartes inicia un camino que, de alguna manera, llega hasta nosotros; decíamos que ese camino está ahora consumado: es decir realizado en su máxima plenitud, al mismo tiempo que cumplido en sus posibilidades y requerido de nuevas orientaciones y metas.t

Dificil, muy dificil es vivir en tiempos de la modernidad consumada. Tiempos en que el esplendor de lo realizado ciega, mientras que el abismo aterra. Tiempos en que la certeza de lo que fue alimenta su restauración (aủn a sabiendas de su imposibilidad); asi como el espectro de ese mismo ser incita su superación (su post). En fin, un difícil entretiempo que podriamos filiar -especulativamente hablando- en la gigantesca labor hegeliana y cuyo fin no aparece claramente a la vista (aún cuando casi lo proclamemos a diario con modas tan fugaces como la gravedad de su falta).

Y es precisamente Hegel quien no sólo tiene conciencia de ese fin, sino de su propio comienzo. El entusiasmo con que comienzan los "tiempos modernos", en sus Lecciones sobre Historia de la Filosofia, habla por si solo: "Aqui, ya podemos sentirnos en nuestra propia casa y gritar, al fin, como el navegante después de una larga y azarosa travesía por turbulentos mares: tierra!".s Del cultivo de esa tierra cartesiana, de su uso y abuso, vivimos hasta el presente: esto quiere decir -y no más- de ese campo de la metafisica del sujeto y sus múltiples, complejas y hasta encontradas variantes. Al cabo de siglos, era lógico que el producto se mejorara, tanto como que la cantera diera muestras evidentes de agotamiento.

A cuatrocientos años del nacimiento de la subjetividad moderna, es justo volver sobre ese signo denominado "Renato Descartes", a condición que simultáneamente asumamos este desafio de su lectura. No hay otra manera, a no ser que la anécdota desplace lo esencial.

Y es asi que - como contemporáneos tardios de Descartes - podria sernos de utilidad diferenciar entre el programa y los contenidos cartesianos. Sabemos no obstante que - precisamente a partir de Hegel- esta diferenciación es dificultosa, cuanto no dialécticamente inválida, pero si nos atrevemos a insistir en ella no es por ignorancia de esa dificultad, sino por que nos resulta propedéuticamente útil. Aclarado lo cual, podriamos decir que muchos puntos del programa cartesiano (aún redefinidos) mantienen cierto aire de su frescura inicial, mientras que la mayoria de sus contenidos han sido alcanzados por la flecha inexorable de la consumación.

Por ejemplo, aún en este "entretiempo", el ideal de la zinidad de la ra-ón —supuesta y clave del programa cartesiano- conserva su validez (reguladora), en medio de una cultura cada vez más fragmentaria, donde la hiperespecialización ha instalado un nuevo feudalismo gnoseológico, con implicancias tangibles en lo teórico y en lo práctico. Asimismo la unidad en ella - su otra cara - no es desdeñable en una cultura necesitada como nunca de convivencia global; claro está, siempre y cuando esa idea de "razón" no sea —como en el pasado- secta. ria y excluyente.

Otro tanto ocurre con la voluntad de critica, que supone la duda metódica, para una cultura que -como la nuestra- está amenazada por la frivolidad, el oportunismo, o un peligroso conformismo ante las nuevas barbaries. Aunque para esto sea necesario extenderla a campos donde Descartes se detuvo.

4 Utilizamos el tármino "consumación" en el sentido en que Heidegger, por ejemplo, lo liace en el primer párrafo de su Ober den H/mranismus: "Consumar quiere decir: realizar algo en la suma, en la plenitud de su esencia, conducir esta adelante, producere".

5 En esas mismas Iorlesungen liamará a Descartes, "un héroe del pensamiento, que aborda de nuevo la empresa desde el principio y reconstruye la filosofia sobre los cimientos puestos de nuevo al descubierto al cabo de mil años". 
Voluntad de critica que iba acompanada de una decidida bisqueda de la verdesd y no se limitaba a celebrar la confusión o, lo que es peor, a levarla a la categoria de una nueva virtud. Momento afirmativo del método que le pernitía evitar las trampas de un deconstructivismo que se esteriliza en su propio gesto, o de un criticismo sin propuestas. Alejados ya de sus contenidos, este gesto afirmativo cartesiano conserva hoy su necesidad.

Finalmente -y sin pretender agotarlo con esto- tenemos además en aquel programa cartesiano ese reconocimiento de la liberlad del hombre y de su responsabilidad para con lo que efectivamente sucede, necesarios en una época que tiende a hacer de la resignación un culto y del desentendimiento su deporte preferido. La vieja doctrina del "libre albedrio" y aquéllas polémicas sobre la preordenación divina y la libertad humana -que la Carta a lsabel de enero de 1646 , plantea con tanta finura-, no son preocupaciones ajenas a este siglo, aun cuando los textos y contextos sean otros.

$Y$ esto último no es precisamente desdenable porque, como hemos dicho, ese programa fue llenando con contenidos especificos. Deciamos que a estos, la fecha de la consumación los habia alcanzado, lo cual debe ser también tomado rigurosamente en cuenta; so pena de oponerle a la pretensión postmoderna una restauración neomoderna, tan ilusoria como la anterior. No se sale de la Modernidad anteponiéndole el prefijo "post." a cada punto de su programa; ni se regresa a ésta — como si nada hubiera pasado- presentándola como incumplida y vigente.

En este sentido, muchos aspectos del actual debate modernidad/postmodernidad ( $y$ otros que le son conexos) ocultan el fondo (le la cuestión. La consumación de la metafísica moderna de la subjetividad - tarea que enlaza a nuestro presente con Descartes- requiere algo más que discusiones, modas y capillas. En esto conviene recordar aquello que ya irritaba a Kant, a propósito de las polémicas mal planteadas, donde los contendientes terminaban adoptando "el aspecto ridiculo que los antiguos expresaban diciendo: uno ordeita al macho y otro tiene el jarro". 6

Para evitarlo, acaso convenga volver - sin prejuicios - sobre algunos contenidos concretos del programa cartesiano.

\section{La revolución ontológica}

Si hoy podemos y debemos seguir pensando a Descartes, es porque su doctrina introduce una marca irreversible en la historia de la filosolia. Su recepción de la herencia clásica, unida a una implacable (y profunda) redefinición, lo ubican como padre de una verdadera revolución ontológica que llega hasta nuestros dias. En el corazón de esa revolución están las nociones de razón y de cogito.

Acaso el supuesto de la unidad de la razón sea la mayor herencia que Descartes recibe de la filosofia clásica - en particular del estoicismo- pero, como bien sabemos, hay una diferencia fundamental: esta ratio no es ya una sustancia divina de la cual el hombre participa, sino una facultad especificamente lmmana, a la cual Dios da garantias si (y sólo si) el hombre se atiene a las reglas que prescribe el Método. La razón se hace ahora sustancia de la subjetividad humana.

Pero ese reconocimiento de la sustancialidad del cogito (Discurso, IV, 33), debe leerse acompanado de una redefinición del clásico concepto escolástico de sustancia (sujeto de cualquier atributo del que tengamos una idea real), transformándose ahora sólo en el pensamiento

6 Cf. Kant, Critica de la Rasón Pura, Doctrina Elemental Trascendental, scigunda parte, introducción, III (B83/A58). 
existente, sin que esto implique el reconocimiento de algún substratum suyo desconocido, sino la relación intrínseca del yo consigo mismo (la cual es "evidente"). ${ }^{7}$

Queda asi constituida la triada susiancia/ra:ón/hombre que de aqui en más y progresivamente, trazará el campo de problemas y preocupaciones filosóficas y cientificas. A su vez Dios —ese peculiar "Dios cartesiano" que ya notara Pascal (Pensées, 556)- desprovisto de todo carácter religioso, autor de verdades geométricas y del orden del mundo, desplazado del centro, pasará a ocupar —en los márgenes- el lugar de un principio de garantía y verdad gnoseológica. A pesar de seguir reconociéndosele - todavía en Descartes- el carácter de una potencia inagotablemente creadora, esa infinitud es más de potencia que de entendimiento; en consecuencia, tendrá una amplia facultad de arbitrio (de decisión), pero es desde ahora el hombre responsable y guia de la razón.

Tenía razón Hegel ("Con Cartesio tocamos tierra..."), al mismo tiempo que nos quedamos solos. Solos en nosotros mismo, aun cuando otros amenazadoramente nos circunden, y solos para poner y disponer de la naturaleza a nuestro antojo, empezando por nuestro propio cuerpo. Liberados de una potencia omnipotente y por momentos asfixiante - no precisamente un paraiso perdido, que pudiera figurar como modelo- el programa moderno se pondrá a trabajar febrilmente. Todo estaba por hacerse o readecuarse... cuatrocientos años no es nada.

De la contemplación, a la acción. La razón - ahora como facultad puramente humanano opera ya descubriendo o manifestando un supuesto orden divino. sino produciendo y estableciendo desde si misma el orden de los conocimientos y de las acciones. Al igual que Bacon, Descartes sabe ahora que el conocimiento es poder $y$-aun con sus vacilaciones y reconocida prudencia- hacia él se dirige metódica y resueltamente: "en lugar de esta filosofia especulativa que se encuentra en las escuelas, es posible encontrar una práctica por la cual conociendo la fuerza y las acciones del fuego, del agua, del aire, de los astros, de los cielos y de todos los demás cuerpos que nos rodean, tan distintamente como conocemos los oficios de nuestros artesanos, los podríamos emplear de la misma manera para todos los usos a que nos sean apropiados, y asi hacernos como dueños y poseedores de la naturaleza" (Discurso, VI, 61/62). De lo cual se derivaria — verdadero anticipo de los sucesivos catálogos de ofertas posteriores!- "la invención de una infinidad de artificios que nos harían gozar sin ningún esfuerzo de los frutos de la tierra y de todas las comodidades que alli se encuentran, sino principalmente para la conservación de la salud" (op. cit., VI, 62); lo que a su vez implica no sólo "liberarnos de una infinidad de enfermedades, tanto del cuerpo como del espiritu", sino también del "debilitamiento de la vejez". Como se advertirá, el actual Proyecto Genoma Humano, en su partida de nacimiento; un largo camino para soñar y trabajar en nuestra propia y muy humana "infinitud" (tecnologias mediante).

Es que si algo debemos a Descartes - con todo lo que de alli se deriva- es el reconocimiento de la sustancialidad del cuerpo. Porque sabido es que en la tradición aristotélica el cuerpo no era considerado sustancia, sino órgano o instrumento de la sustancia alma; que en el agustinismo si bien hay ya cierto reconocimiento de la sustancialidad del cuerpo, ésta es todavía parcial o imperfecta. Sólo en el cartesianismo el cuerpo adquiere una plena (y distinta) sustancialidad; sólo desde él se abre cl ancho y problemático campo (bien lo sabemos ahora) para el estudio cientifico del cuerpo humano y su vasta manipulación técnica. Devenido hoy verdadero modelo para armar (trasplantes o implantes mediante) o recombinar (ingenieria genćtica

7 De aqui en más las citas de textos cartesianos es según primera edición de Charles Adam y Paul Tannery, Onres de Descarses, L. Cerf., Paris. 1897/1910, XII volúmenes. 
de por medio), como en tantas otras cosas el buen Renato abrió aquí una puerta tan necesaria como incierta.

Y no se limitó solamente a esto, junto con la puerta de nuestro propio cuerpo, nos abrió las del mundo sin más.

\section{La voluntad técnica}

Porque en realidad, nada es más parcial que hacer de Descartes el simple postulador de la subjetividad. Lejos de ello, el principio del cogito no encierra al hombre en sí mismo sino que -a través de las ideas- lo relanza al mundo.

Pensar es ahora tener "ideas" y esto es una novedad terminológica típicamente cartesiana. En la escolástica este término estaba reservado a la esencia o arquetipo de las cosas subsistentes en la mente de Dios (el universal ante rem); desde Descartes la idea es "la forma de un pensamiento, por la inmediata percepción de la cual soy consciente de ese pensamiento" (Respuestas, II, Der. 2). Pero esto tampoco agota la entidad de la idea, a esta noción de la idea como acto de pensamiento, Descartes le agrega la idea como representación de un objeto (como "cuadro" o "imágenes", asi las llama, de las cosas). Y esto si abre plenamente la razón al mundo. Se inicia aquélla "época de la imagen del mundo", ${ }^{8}$ a cuya representación sigue inexorablemente su dominio (técnico), y en cuya consumación nos movemos cuatrocientos años después.

$Y$ en esto juega — como también se sabe- un papel clave el reconocimiento de la exfensión como carácter esencial de los cuerpos (Principios, II, 4). Extensión que se configura como espacio geométrico, una vez que se abstraen de los cuerpos sus propiedades, quedando asi reducidos a su atributo fundamental (op. cit., II, II).

Reducción que a su vez posibilita el riguroso mecanicismo que dominará toda la tisica cartesiana (y moderna), al limitar las propiedades de la materia a la divisibilidady a la movilidad de las partes (op. cit., II, 23).

Queda asi delimitado el terreno sobre el cual la creciente voluntad técnica puede ejercer ahora su investigación y su dominio. Sin más limites que la eficiencia en el mercado y un simbólico llamado a la prudencia, la producción técnica y el cúınulo de objetos asi resultantes serán la companía y el juego preferidos del hombre moderno.

La revolución ontológica va cobrando asi -cada vez más- su rostro técnico, a punto tal que hoy son prácticamente una. Desplazado Dios (tinalmente nuerto), los juguetes técnicos se han vuelto prácticamente nuestra única (y fascinante) compañia. En su producción y adquisición finca buena parte de aquello que, por costumbre, todavia seguimos Ilamando "felicidad". $Y$ por la cual, desde Descartes, venimos paganda un precio individual y social, singularmente alto.

\section{Acciones, pasiones y... razones}

En efecto, la entrada del hombre en el centro de la escena, la entronización de la rizón calculante como medida y método y esa apertura inperial y dominadora sobre el mundo. exigió a su vez una redetinición fundamental de esos mismos tres conceptos (hombre, razón y mundo). Detengámonos ahora brevemente en el primero.

8 Sigo en esto la expresión de lleidegger en la tonferencia homónima incluida en /lolale'ge (Gesammansgabe.

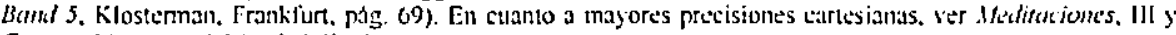
Carta a Merscme del 16 de julio de 1641 . 
Descartes es también aqui sólo el inicio y, como tal, el que apunta en una dirección. Esta marca la necesidad de una fucrte represión de las pasiones y de una decidida domesticacion de la voluntad, única forma en que la razón extienda su dominio a lugares todavía no alcanzados. Porque si bien es cierto que las pasiones (y todo lo que a cllas concierne) no gozaban precisamente de favor en el mundo escolástico, también lo es que -dentro del proyecto racional moderno- esa hostilidad se agrava ciertamente.

Si bien todavia en Descartes las pasiones no son dañinas en si mismas, y la tristeza y la alegría cumplen una función natural y positiva en la preservación de la salud del cuerpo (Pasiones, II, 137), el juicio definitivo hacia ellas no termina siendo favorable: distorsionan las nociones de bien y de mal $y$, en consecuencia, infunden a nuestras acciones más ardor del conveniente (Pasiones, 11, 138). De aqui se sigue un programa netamente represivo (vencerlas y detener los movimientos que las acompañan), de cuyos resultados - cuatrocientos años después- no podemos precisamente vanagloriarnos.

Tampoco le va mejor a la volumtad, de quien dependen las acciones. Si a las pasiones le debemos la desmesura respecto del bien y del mal, a la voluntad debemos computarle al posibilidad del error (Mfeditaciones, IV y Principios, I, 34). Dotada - por el libre albedrio- de la capacidad de afirmar y negar, es ella la principal causa en la precipitación del entendimiento. De aqui que, asi como hace falta reprimir las pasiones, es necesario domesticar la voluntad: esto es someterla metódicamente a la razón.

Como dijimos - a juzgar por los resultados-ese programa de represión y domesticación no ha sido precisamente exitoso. ¿Acaso porque todavia no hemos sido suficientemente racionales?; ¿o más bien porque poco podia ( $y$ puede) esperarse de una razón montada a expensa de las pasiones y de la voluntad?. ¿La única razón posible es la razón que somete?; ¿o puede todavia pensarse en una razón reencontrada con las pasiones y reconciliada con la voluntad?

¿No es acaso ya necesario y urgente elaborar una nueva teoria de la prudencia, que vaya más allá de la recomendación de extender el dominio de la razón sobre las pasiones? (Pasiones, III, 21I)?.

Sin embargo esto no es todo, ya que este hombre (redefinido) que ha entrado en la escena moderna, no es sólo un ser individual, sino también una moral y una politica.

En cuanto al dominio de la moral, hay ciertos contenidos con los cuales Descartes inicia el camino que llega hasta nosotros. ${ }^{9}$ De entre ellos convendria reparar en esa peligrosa escisión entre lo piblico y lo privado, que supone la "primera regla". Esto -que si bien Descartes en lo personal le permitiria la supervivencia, en un mundo de guerras y fanatismos cotidianosharás de allí en más peligrosa escuela, al servicio de causas mucho menos nobles e imperiosas. En efecto, aquella respuesta al ministro protestante Revius ("Tengo la religión de mi rey y de mi nodriza"), se fundamenta en el perfecto distingo de dos órdenes diferenciados y hasta antagónicos: de un lado, el "uso de la vida", donde la voluntad tiene la obligación de decidirse, aun sin esperar la evidencia; del otro, el "dominio de la contemplación", en el que el hombre no puede conformarse más que con la verdad evidente (Respuestas, Il y Discurso, III).

Con el primero - $\mathrm{el}$ del, poder efectivo - no se juega, se lo acata y se lo respeta. Sólo en la intimidad del segundo, es posible el ejercicio (en soledad) de una cierta libertad. Peligroso dualismo al cual debemos algunas de las peores páginas de nuestra historia contemporánen: no pocos totalitarismos y fanatismos; casi todos nuestros confortables "renunciamientos" y ese

9 En el tema moral tenemos en cuenta la usual distixción entre una "moral provisoria" (Discurso, lil) y la que puede considerarse "definitiva" (Carras a la princesa /sabel y Pasiones), por correcciones del propio Discartes. 
desinterés por lo público, justificado precisamente desde una hipervaloración de lo privado (concebido ahora como el único lugar donde la razón y la libertad son posibles).

Por lo tanto, la libertad se vuelve un hecho intimo, constitutivo de la conciencia individual, de la cual nos percatamos en nuestra pura experiencia interior (Principios, I, 39).

Y como todo lo "otro" anenaza mi libertad, o me resta soberania, asistiremos a progresivas añadiduras: el indisoluble matrimonio de la libertad con la propiedad; la "inocente" y lasta amable sentencin, según la cual la "libertad mia termina donde empieza la del otro" (en función de lo cual semejante pasa a ser una amenaza) y - por fin- la constncción de una noral y de una política, donde las nociones de solidaridad y de justicia, no dejan de ser amables, pero secundarias, recomendaciones.

Es asi que - rodeado por el poder y dominado esencialmente por el miedo- aparece aquélla definición egoista de la libertad, según la cual ésta reside en la amtosuficiencia personal que experimentamos, al no sentir en nosotros otra fuerza que la propia razón (Mleditaciones, IV). Entonces, otra vez la soledad, es decir el amurallamiento en un yo condenado - al unisono- a conquistar y a temer... Y ya sabemos de lo que es capaz un "burgués asustado": de los diversos totalitarismos al hombre "light", hay un interesante catálogo en el siglo xx.

Sin embargo, es también el tiempo y la oportunidad de seguir avanzando. Lo bueno de un tiempo de consumación como el que vivimos, es que la pesadez - paradójicamente- también se vuelve liviandad y la historia es tanto tradición. cuanto puente hacia otra cosa. Después de todo, fue el propio Descartes quien nos puso en el centro de la escena y ensenado que no todo depende de los dioses.

\section{Más allá de la modernidad consumada}

Sin embargo, cuatrocientos alos después, lo peor que podría pasamos es repetir monótonamente a Descartes o, peor aún, archivarlo en el desván de las ideologias en desuso. No sólo sería injusto, sino también insensato.

Para nosotros, latinoamericanos, tiente además un sabor muy especial: sus obras integraban el prolijo Index que las autoridades coloniales españolis habian elaborado, acaso para "proteger" nuestras jóvenes - aunque calenturientas - mentes americanas. Y ya se sabe la fascinación especial que ejerce lo prohibido.

Junto con Rousseau, Voltaire y algún que otro "revoltoso" de la época, leer a Descartes -salvo raras excepciones- podia ser un ingrato pasaporte al otro mundo. Porque como bien se sabe allá —como aquí-, la Inquisición y el funcionariado colonial no habian hecho suyo ese programa cartesiano de represión de la pasiones y domesticación racional de la voluntad; ni mucho menos aquello de la "universalidad" de la razón, cuando los indios, criollos o "sudacas" se trataba. Aunque - justo es reconocerlo- tampoco los compatriotas de Descartes fueron demasiado cartesianos en sus colonias americanas.

Curiosamente, sólo pudimos leer a Descartes en paz, práclicamente al mismo tiempo que sus restos terminaron descansando en Sain-Germain-des-Pres, después de 169 años de vicisitudes y aquél entierro sueco de 1650 (itrónicamente en un cementerio para "ninos privados del uso de la razón"!). Nosotros también, como Descartes, tuvimos durante muchos años la cabeza por un lado y el cuerpo por el otro, al calor de la pasión de un capitán bravio que la cortó y vendió al mejor postor, ignorando también toda recomendación racional del maestro.

Sin embargo, en este cierre de siglo, sabemos "con claridad y distinción" que nos hallamos en el mismo barco y' que no se tripula esta nave espacial Tierra con viejos manuales (aunque cada tanto alguien lo intente). Acaso por eso tengamos hoy tareas comunes - junto a las 
que nos son inexorablemente propias-; simbólicamente hablando, se trataria de recorrer las calles que van desde el Museo del Hombre (donde se exhibe, en un acto de curioso gusto, la cabeza de Descartes), hasta la Iglesia de Saint-Germain, donde descansan sus restos mortales y juntarlos. Tanto a europeos como a americanos nos haria bien.

En términos mas estrictamente conceptuales, esto implicaria realizar la consumación de la metafisica moderna y asi, efectivamente, poder asumirla y sobrepasarla hacia horizontes diferentes. En términos de la razón es necesario — con toda urgencia y sensatez- pensar los nuevos motivos de su unidad (que ya no podrá descansar en la simpleza de la "sustancia", ni en el reconocimiento abstracto de su "universalidad"). Razón que tampoco podrá pensarse contra la vida, exigiendo sin más la represión de las pasiones y la domesticación de la voluntad (dudoso programa que, en espiral creciente, requerirá siempre más); por el contrario, es necesario su reencuentro, para que la psicosis no reemplace a la cultura sino que - por el contrario- la posibilite. Se trata por fin de una racionalidad menos dominadora y mucho más dialógica; donde la necesaria relación entre la técnica y la naturaleza sea precisamente eso y no una suerte de combate a muerte con pésimo pronóstico. Una razón abierta e intercultural, donde el universal abstracto de la razón moderna (ontológicamente imperial), ceda su lugar a las universalidades situadas de culturas que, desde su arraigo efectivo, posibiliten lo planetario como juego irreductible de las diferencias, antes que un previsible monólogo de bloques o supuestos "centros".

Todo lo cual a su vez será imposible si - junto con la noción de racionalidad- no redefinimos la de hombre. Es aqui también de toda urgencía liberarlo a éste de las ataduras del "sujeto" y de las trampas de la "subjetividad", en que la propia Modernidad lo encasilló. Lo cual paradójicamente, nos hace perseverar en su soinado programa emancipador de ataduras, complctándolo y al mismo tiempo redetiniéndolo. No se trataba de codear a Dios para poner al lombre en su lugar (reemplazando una usurpación por otra), sino más bien de intentar la aventura - siempre tensa- de su convivencia enigmática. Lo cual de suyo implica evitar las simplificaciones del "hombre máquina" y del Dios "relojero", en que la filosofia $y$ la teología modernas, por distintivas vias, desembocan.

Hay que revisar también ese enorme conjunto de "objetos" que le son correlativos, en una naturaleza concebida como depósito de mercaderias a ser puestas en el mercado por el trabajo humano.

Después de todo, acaso no sea más que la singular tarea de recuperar - tanto a los dioses, como a los hombres y a las cosas- de su moderna soledad. Algo asi como evitar que el mundo termine por convertirse en un gran Macondo. 